\title{
Sulfur Trioxide Micro-Thermal Explosion for Rice Straw Pretreatment
}

\author{
Ri-Sheng Yao and Feng-He Li \\ Additional information is available at the end of the chapter
}

http://dx.doi.org/10.5772/50428

\section{Introduction}

With the gradual depletion of fossil energy resources in the global scope, the conversion of cellulose into biofuels attracts considerable attentions, since it is the most abundant renewable polysaccharide on the earth. The main sources of cellulose are woods, agricultural residues, hydrophytes and straws (Dieter and Thomas et al. 2003; Hon, 1996). Rice straw is a frequently abandoned crop straw in Asia and is often burned. This wastes cellulose and pollutes the air. Thus, utilizing rice straw to produce biofuel has promise. Generally, the procedure of converting rice straw into fuels is removal of the protective lignin first, followed by transformation of cellulose into glucose and at last, converting these sugars to biofuel by fermentation.

Removing lignin is critical to utilizing cellulose (Reith et al. 2003). Lignin content, crystallinity and particle size, limit the digestibility of cellulose (Hendriks and Zeeman, 2009). Therefore, various pretreatments remove or alter the hemicellulose or lignin and decrease the crystallinity of cellulose to enhance enzymatic hydrolysis efficiency (Goering, et al., 1970; Mosier et al., 2005; Zhao et al., 2009). The major methods include pretreatment by milling (Sato et al., 2009; Delgenés et al., 2002; Chang and Holtzapple, 2000; Palmowski and Muller, 1999), acid (Keikhosro K, 2006; Nguyen, Q, 2004; Ye and Jay, 2005; Taherzadeh and Karimi, 2007; Iranmahboob, F, 2002), steam explosion (Mukhopadhyay and Fangueiro, 2009; Brownell et al., 1986; Negro et al., 1992), liquid hot water (Liu and Wyman, 2005), alkali (Das and Chakraborty, 2009; Goswami et al., 2009; Fengel and Wegener, 1984; Laser et al., 2002), wet oxidation (Palonen and Thomsen, 2004; Kumar and Wyman, 2009), ammonia fiber explosion (AFEX) (Taherzadeh and Karimi, 2008; Li et al., 2009; Zheng et al., 1998; Wu et al., 1999), $\mathrm{SO}_{2}$ catalyzed steam explosion (Balint and Emma, 2010) etc. Although these common pretreatments have made great successes in recycling cellulose from lignocellulosic biomass, they are not appropriate enough for biofuel production by industrialization if considering 
the disadvantages of them such as low efficient, huge energy consumption, high requirements for conditions of operations, environment pollution and so on.

Recently, rice straw has been pretreated with, ionic liquid (Vitz, J. and Erdmenger, 2009), low-temperature plasma ( $\mathrm{Li}$ and $\mathrm{Yao}, 2012)$, microwave-assisted dilute lye ( $\mathrm{Li}$ and Yao, 2012). In this chapter, we concentrate upon the novel pretreatment method of rice straw based on sulfur trioxide micro-thermal explosion (STEX), the moderate conditions for the operation of this pretreatment method make it a promising technology to reduce costs and increase the utilization of lignocellulosic cellulose.

\section{Principles of sulfur trioxide micro-thermal explosion}

The principles of STEX can be described by the model diagram shown in Fig.1. sulfur trioxide $\left(\mathrm{SO}_{3}\right)$ gas diffuses into the interior of rice straw through its capillary channels, reacts with the water in the tissue space and surface. As a result of violent exothermic process of the reaction, the gas in the limited tissue space expands and an in-situ detachment between the cellulose and the lignin will occur, moreover, lignin will be sulphonated partly during this process which may increase the solubility of the lignin in dilute lye. The operation can be performed under atmospheric pressure at about $50^{\circ} \mathrm{C}$, it makes the subsequent treatment of stripping off lignin by dilute alkali solution more effectively as compared to the procedure by dilute alkali only (Yao and Hu etc. 2011).

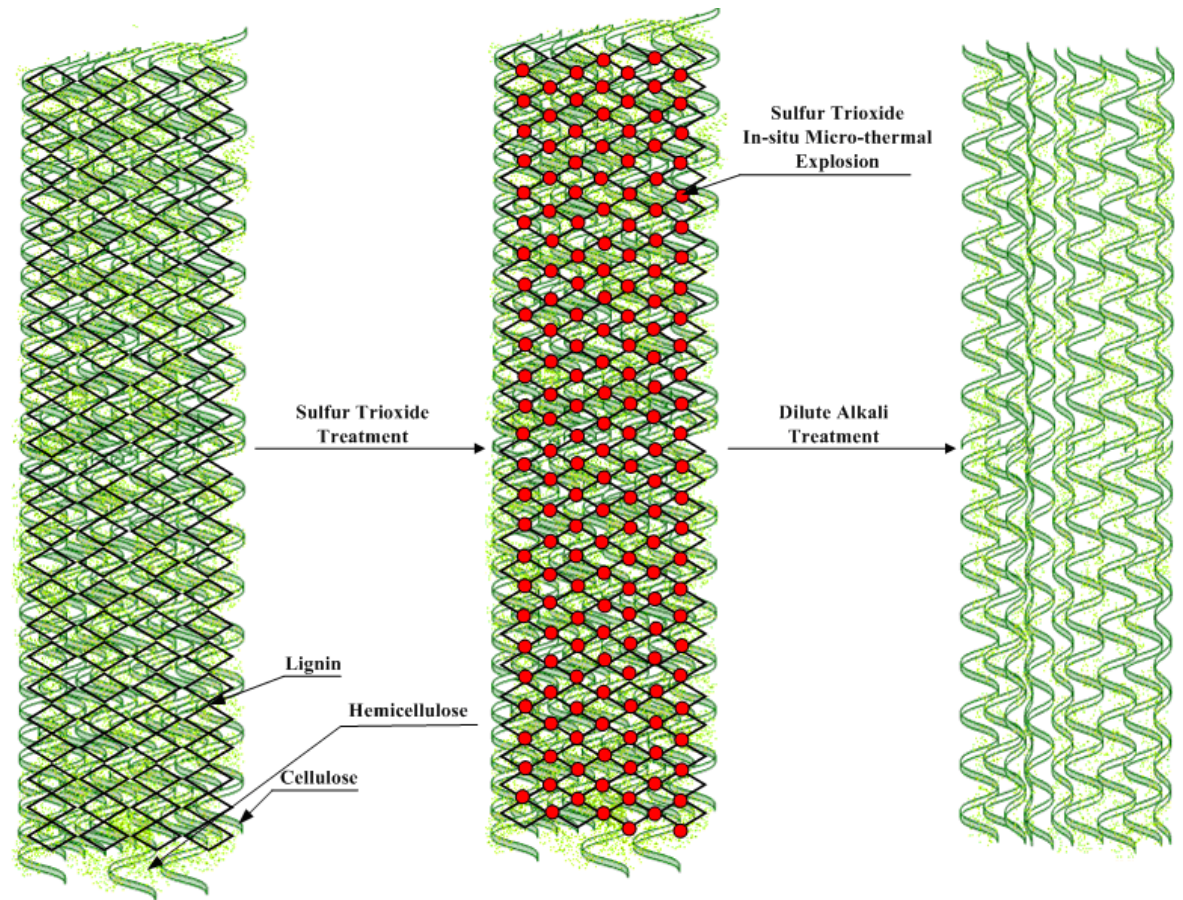

Figure 1. STEX collaborative dilute alkali model diagram 


\subsection{Gas diffuse and chemical exotherm in situ generating explosion}

Comparing to liquid, gas diffuses more quickly and deeply into interior of rice straw through its capillary channels. When $\mathrm{SO}_{3}$ gas accesses to the interior of rice straw, microthermo explosions take place as a result of reaction between $\mathrm{SO}_{3}$ and water remaining in the pores of the rice straw, which make great changes of the interior structure of the rice straw.

The capillary channels presence in the original straw are arranged irregularly and some of its opening have been blocked (Fig.2A). The blocked openings are not conductive to the entry of cellulose hydrolysis enzyme. After straw is treated by $\mathrm{SO}_{3}$ gas, the channels in the straw increase and are bundled, as if the internal structure of the straw are "hollowed out" (Fig.2B), which will promote the access of the substances during the subsequent handling. With increase of the STEX time, the channel structure becomes more obvious (Fig.2C). However, when the STEX time is more than $60 \mathrm{~min}$, channels aggregate together and become not so obvious (Fig.2D and Fig.2E). The elongated STEX time may cause the internal environment of the straw more acidic, and induces acid hydrolysis, thereby major components of the rice straw degrade and the structure of the rice straw is damaged.

\subsection{Procedure of sulfur trioxide micro-thermal explosion collaborative dilute alkali}

The STEX for rice straw is convenient and can be performed under atmospheric pressure at about $50^{\circ} \mathrm{C}$. A typical procedure of this method in the laboratory can be divided into two steps: First, $1 \mathrm{~g}$ rice straw is cut into small pieces of about $2-3 \mathrm{~cm}$ in length, and hung over the upper portion of a test tube with $1 \mathrm{~mL}$ oleum (Sulfur trioxide $50 \%$ ) loading in the bottom, after raising the temperature of the system to $50^{\circ} \mathrm{C} \mathrm{SO} 3$ gas is generated and reacts with the upper straw for $5 \sim 120 \mathrm{~min}$. Second, the as-prepared rice straw is soaked in $\mathrm{NaOH}$ solution $(1 \%, \mathrm{w} / \mathrm{v})$ with the solid-liquid ratio of $1: 10$, the mixture is stirred at $90 \mathrm{rpm}$ with placing the reaction flask in a water bath at $50^{\circ} \mathrm{C}$ for $2 \mathrm{~h}$, then the solids are washed with $800 \mathrm{~mL}$ of deionized water before the subsequent enzymatic hydrolysis procedure.

\section{Structure of rice straw pretreated by $\mathrm{SO}_{3}$ gas}

STEX undermines the structure of straw at a microscopic level that makes it conducive to the subsequent alkali stripping. In this section, the results of scanning electron microscope (SEM), X-ray diffraction (XRD), and fourier transform infrared (FTIR) spectroscopy will reveal the effects of STEX on rice straw.

\subsection{Surface morphology and crystallinity}

\subsubsection{Surface morphology observation by SEM}

The microscopic morphologies of pretreated-straws are shown in Fig.3. Regarding the untreated straw, a compact structure comprised of plant cell wall compositions such as 


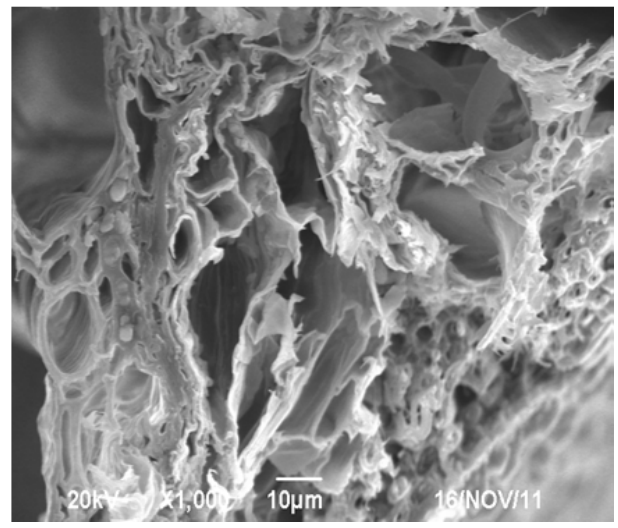

(A)

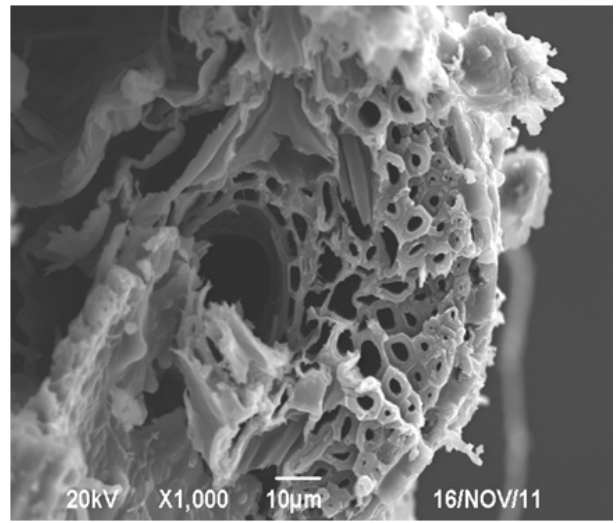

(C)

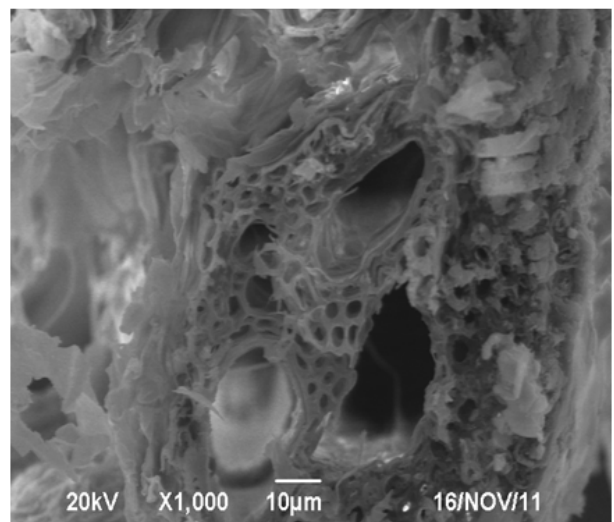

(B)

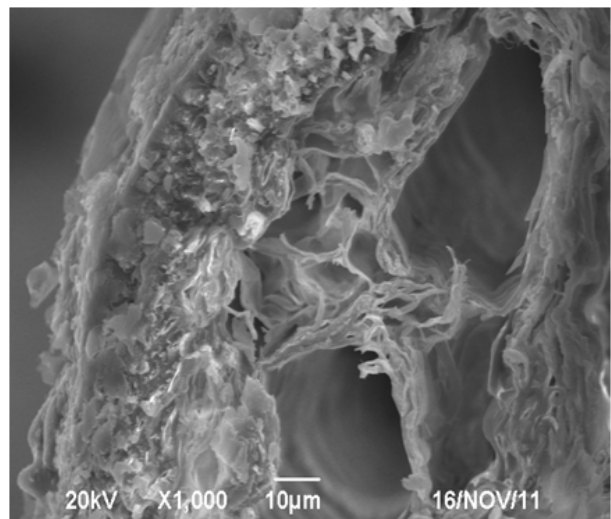

(D)

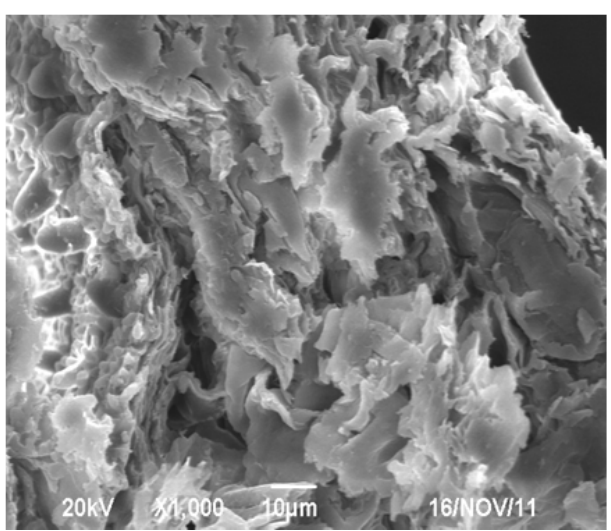

(E)

Figure 2. SEM of rice straw cross-sectional with the STEX, A-original straw, B-STEX 15min, C-STEX 30min, D-STEX 60min, E-STEX 120min. 
epidermis, vascular bundles, lumens, dents and parenchyma still remains. To the rice straw treated by sulfur trioxide, the flaking traces and some holes can be observed on the straw surface (Fig.3B). As mentioned previously, gaseous sulfur trioxide can react with water in straw and release great heat in-situ at the same time. As a result, the air and water vapor in the limited interior spaces of the straw expand sharply to make a hot explosion from the interior and cause effective detachment between cellulose and lignin; it makes the subsequent removal of lignin with dilute lye more efficient. As shown in Fig.3C, vesicle shaped particles were stripped away effectively and exposures of cellulose filaments were significant after treatment of STEX treated-straw with $1 \% \mathrm{w} / \mathrm{v} \mathrm{NaOH}$ for 2 hours at $50^{\circ} \mathrm{C}$.

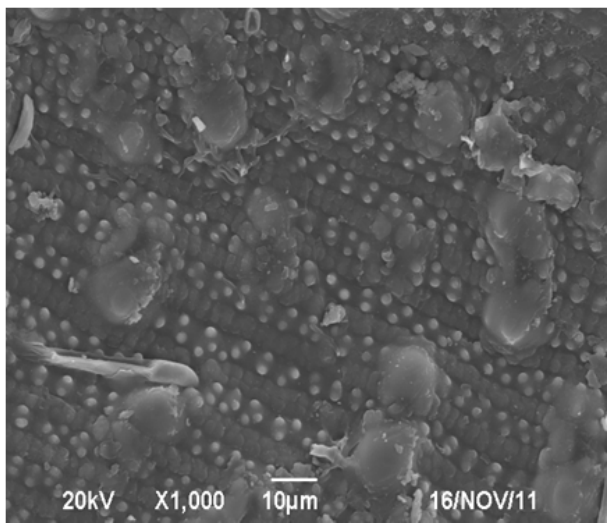

(A)

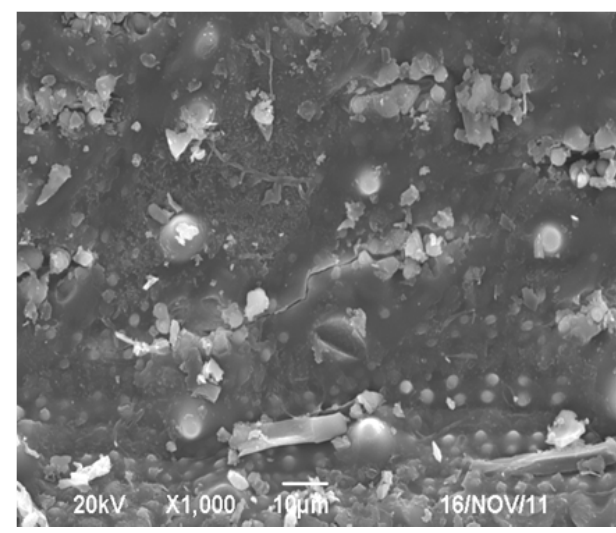

(B)

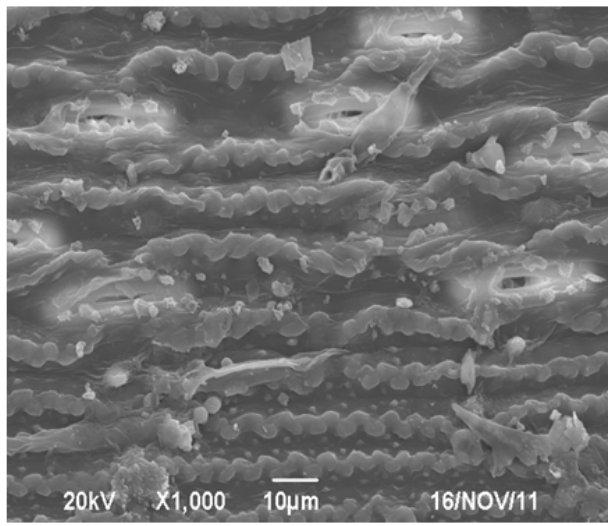

(C)

Figure 3. SEM imagines of straw samples with different treatment. A-original straw, B-STEX treatedstraw, C-STEX collaborative dilute lye treated-straw

The disruption of the vesicle structure increases with reaction time between rice straw and $\mathrm{SO}_{3}$ (Fig.4). In our experiments, when the reaction time was prolonged to $120 \mathrm{~min}$, the structure of rice straw was almost completely ruptured. 


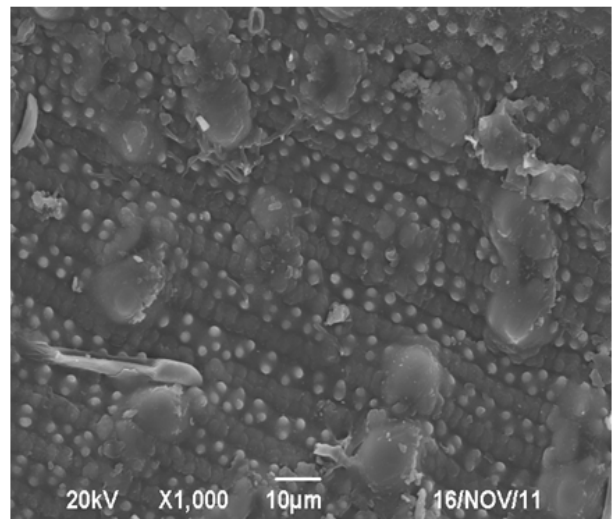

(A)

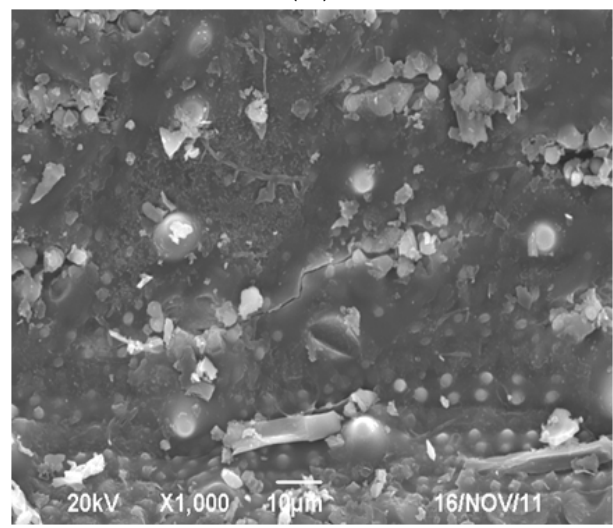

(C)

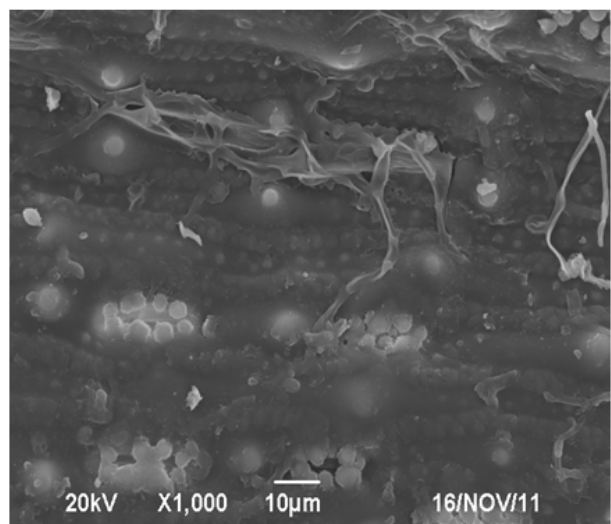

(B)

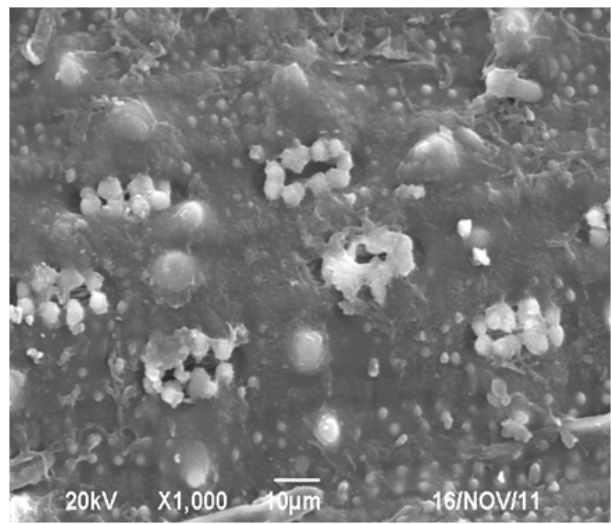

(D)

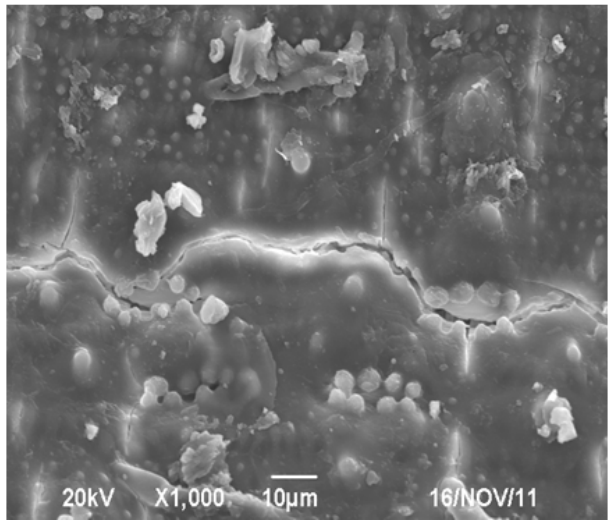

(E)

Figure 4. The SEM images of straw with different STEX time, A-untreated, B-STEX 15min, C-STEX 30min, D-STEX 60min, and E-STEX 120min 


\subsubsection{Crystalline analyzed by X-ray diffraction $(X R D)$ and the influence of saccharification rate}

Crystallinity of cellulose is one of the main obstacles for enzymatic hydrolysis. STEX can reduce the crystallinity of rice straw effectively especially after the assistance of subsequent dilute lye. As shown in Tab.1, the effects of sulfur trioxide collaborative dilute alkali method are remarkable on the crystallinity and saccharification rate of the rice straw comparing with the ones of untreated, sulfur trioxide-treated only, alkali-treated only methods. Although sulfur trioxide-treated method decreases the crystallinity of cellulose, it doesn't significantly improve cellulose hydrolysis without the collaboration of dilute alkali. This result may imply that there are more profound changes occurring on contents and chemical structures of the straw during the process of the pretreatment.

\begin{tabular}{ccc}
\hline Pretreatment & Crystallinity(\%) & Sugar conversion rate (\%) \\
\hline (A) & $64.7 \pm 0.6$ & $22.2 \pm 0.8$ \\
(B) & $58.5 \pm 0.3$ & $41.8 \pm 0.4$ \\
(C) & $55.8 \pm 0.7$ & $64.3 \pm 0.6$ \\
(D) & $51.3 \pm 0.4$ & $91.7 \pm 0.4$ \\
\hline
\end{tabular}

Table 1. Pretreatment of rice straw had the crystallinity and the rate of saccharification

Sugar conversion rate from pretreated rice straw was calculated as follows: (EQ1)

$$
S R=\frac{R G}{R S} \times 100 \%
$$

where RG is the dry-weight of reducing sugars in enzyme hydrolysis supernatant, RS is the dry-weight rice straw in pretreated solids.

\subsection{Contents and chemical structures}

\subsubsection{Fourier transforms infrared (FTIR) spectroscopy}

Differences between the IR spectra of the untreated, sulfur trioxide-treated and sulfur trioxide collaborative dilute alkali-treated rice straws confirm changes of the rice straw occurring on the chemical level during STEX. As shown in Fig.6, the absorption bands at $3317 \mathrm{~cm}^{-1}$ (O-H stretch vibration), 2919 and $2850 \mathrm{~cm}^{-1}$ (C-H stretch vibration), $1630 \mathrm{~cm}^{-1}$ (C=C stretch vibration) and $1037 \mathrm{~cm}^{-1}(\mathrm{C}=\mathrm{O}$ stretch vibration) are characteristics of the original rice straw. After rice straw is treated by sulfur trioxide, new peaks at $1147 \mathrm{~cm}^{-1}$ ( $\mathrm{S}=\mathrm{O}$ stretch vibration) and $876 \mathrm{~cm}^{-1}$ (C-SO stretch vibration) appear. To the rice straw treated with sulfur trioxide collaborative dilute alkali, the peaks about $1147 \mathrm{~cm}^{-1}(\mathrm{~S}=\mathrm{O}$ stretch vibration) and 876 $\mathrm{cm}^{-1}$ (C-SO stretch vibration) disappear. These results indicate that lignin is sulphonated partly, then this part is been stripped on the processing with dilute lye. We suggest that not only the detachment between lignin and cellulose but also sulphonation of lignin during STEX may play an important role to the final lignin removal, which means the collaboration of dilute alkali is necessary. 


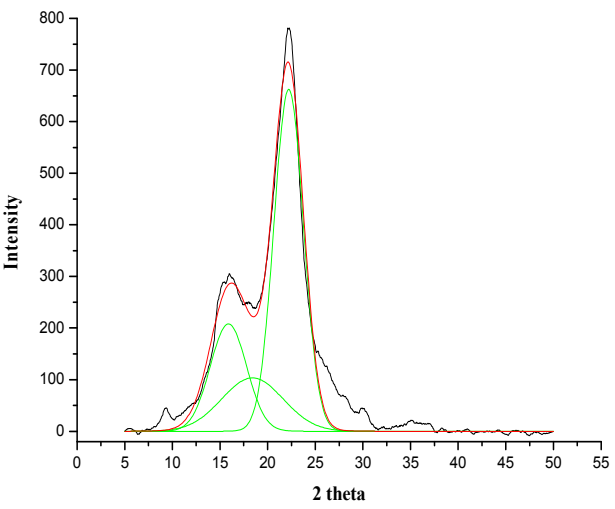

(A)

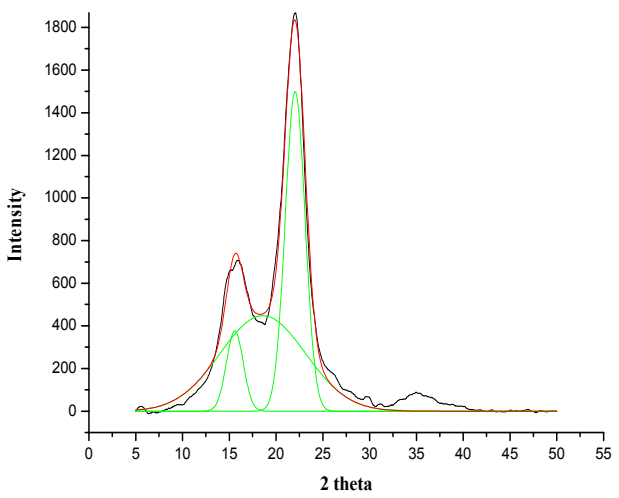

(C)

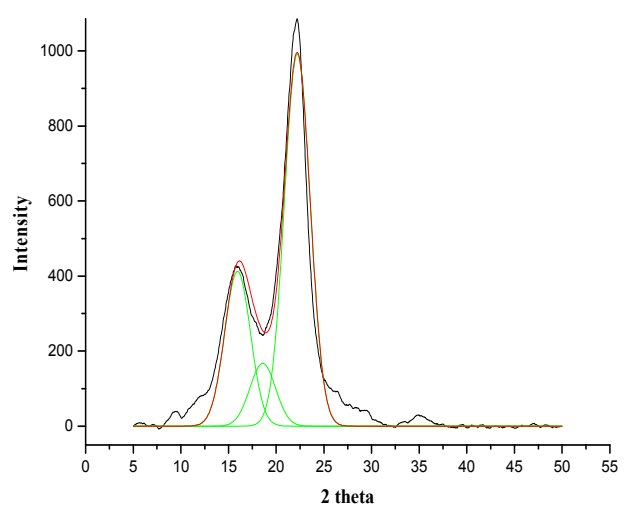

(B)

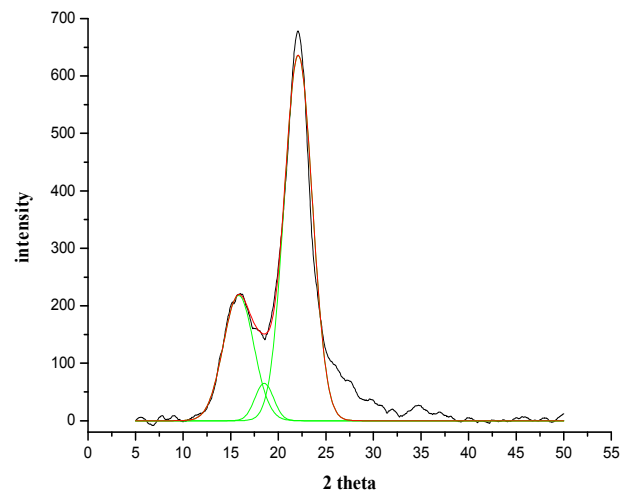

(D)

Figure 5. X-ray diffract diagram: (A) untreated rice straw; (B), rice straw was treated for $30 \mathrm{~min}$ at $50^{\circ} \mathrm{C}$ by sulfur trioxide; (C), rice straw was treated for 7 hours at $50^{\circ} \mathrm{C}$ by $1 \% \mathrm{w} / \mathrm{v} \mathrm{NaOH}$. (D), straw was treated with sulfur trioxide for $30 \mathrm{~min}$ following $1 \% \mathrm{w} / \mathrm{v} \mathrm{NaOH}$ treatment for 7 hours at $50^{\circ} \mathrm{C}$

\subsubsection{Changes of main components in rice straw}

The quantities of the components of rice straw change a lot after being treated with STEX collaborative dilute alkali. Results from our work are shown in Table 2. The composition was calculated based on the dry weight of the samples and we found that water-soluble content of the STEX-treated rice straw increased. It indicates water soluble molecules such as oleoresin, lignin/hemicellulose fragments and sulphonated matter have more chances to contact water after STEX-treated. Moreover, the lignin and hemicellulose of the rice straw pretreated by STEX collaborative dilute lye decreased from $19.6 \%$ to $6.9 \%$ and $21.4 \%$ to $13.5 \%$, respectively. 


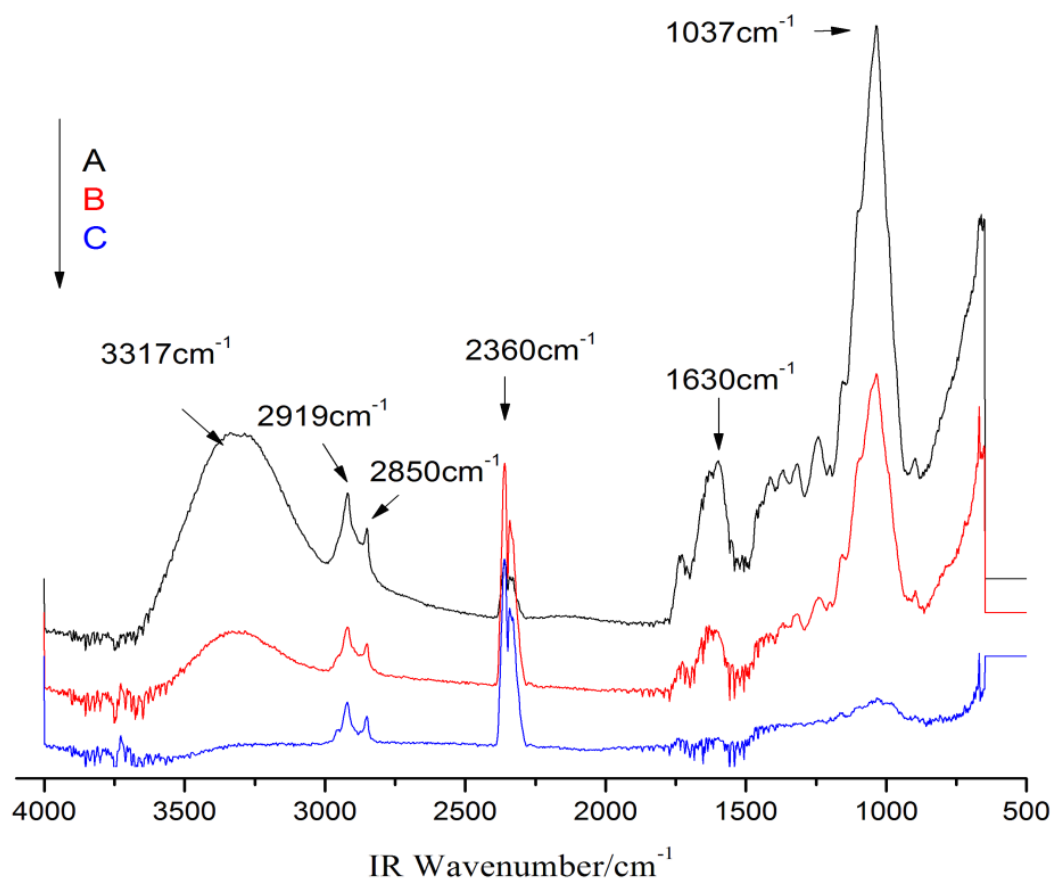

Figure 6. FTIR spectra: A-Untreated-straw, B-STEX treated-straw, C-STEX collaborative dilute alkali treated-straw.

\begin{tabular}{cccc}
\hline Composition $(\%)$ & $\begin{array}{c}\text { Untreated straw } \\
(100.0 \mathrm{~g})\end{array}$ & $\begin{array}{c}\text { STEX treated straw } \\
(100.8 \mathrm{~g})\end{array}$ & $\begin{array}{c}\text { STEX assist lye treated } \\
\text { straw }(73.6 \mathrm{~g})\end{array}$ \\
\hline Water-Soluble & $14.1 \pm 0.2$ & $15.9 \pm 0.4$ & $8.6 \pm 0.5$ \\
Cellulose & $39.2 \pm 0.7$ & $39.8 \pm 0.5$ & $65.8 \pm 1.0$ \\
Hemicellulose & $21.4 \pm 0.4$ & $20.4 \pm 0.6$ & $13.5 \pm 0.3$ \\
Lignin & $19.6 \pm 0.8$ & $18.4 \pm 0.3$ & $6.9 \pm 0.6$ \\
Ash & $5.7 \pm 0.1$ & $5.5 \pm 0.4$ & $5.2 \pm 0.3$ \\
\hline
\end{tabular}

Table 2. Chemical composition (percent by dry weight) of rice straw

The cellulose content increased from $39.2 \%$ to $65.8 \%$, that is predominantly attributed to the decrease of lignin and hemicellulose. Removal of lignin can reduce the binding of lignin to hemicellulose/cellulose (Han et al. 1997; Lu et al. 2002; Ahola et al. 2008; Ma et al. 2008), and more removal of hemicellulose implies that the connections between the hemicellulose and cellulose are broken and more cellulose is exposed. In summary, STEX collaborative diluted lye pretreatment will partly break the lignocellulose structure, enhance enzymatic biocatalysis, increase the desired products yield and recycle more cellulose. 


\section{Saccharification and fermentation for bioethanol production}

Producing ethanol from lignocellulosic materials need a series of chemical and biological procedures, namely opening the bundles of lignocelluloses in order to access the polymer chains of cellulose and hemicellulose, polymers hydrolysis to achieve monomer sugar solutions, fermentation of the sugars to obtain ethanol solution (mash) by microorganisms, purification of ethanol from mash by distillation and dehydration. Figure 7 is a flow figure designed for applying the technology of STEX for producing bioethanol.

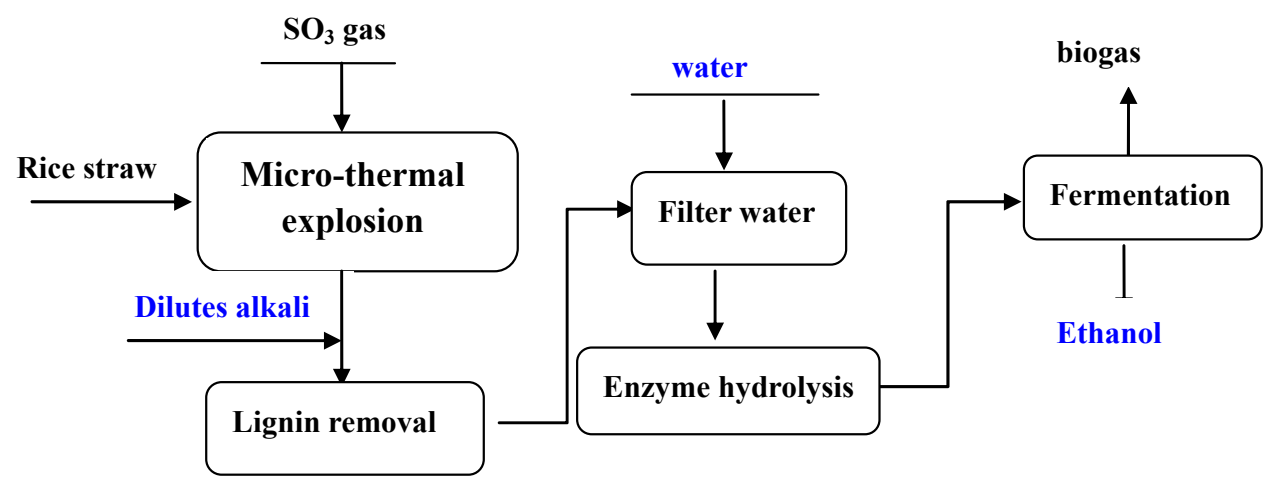

Figure 7. Flow diagram for bioethanol production from rice straw

\subsection{Saccharification with enzymatic hydrolysis}

\subsubsection{Water retention value (WRV) of celluloses}

The structure of untreated rice straw is nonporous and tight. The compact structure makes it difficult to moisturize the interior of rice straw and prevents from entering of the cellulase dissolved in water, which will decrease the efficiency of the enzyme hydrolysis. Hence, water retention value (WRV) of cellulose is often used to evaluate accessibility of cellulose for enzyme and we used it to evaluate the effects of the SO3 micro-thermal explosion. The straw water retention values were determined by centrifugation method. The straw was soaked in water at $25^{\circ} \mathrm{C}$ for $30 \mathrm{~min}$, then centrifuged at $3000 \mathrm{rpm}$ for $15 \mathrm{~min}$. The wet straw was weighed after centrifuging and then reweighed after being dried at $90^{\circ} \mathrm{C}$ for $2 \mathrm{~h}$, The WRV was calculated as the amount of water which retained in the rice straw after centrifuging comparing with dried weight of straw (Eq2)

$$
W R V=\frac{W_{w}-W_{d}}{W_{d}} \times 100 \%
$$

\subsubsection{Water retention value and change of saccharification rate}

The impacts of pretreatment manners to WRV and saccharification rate are shown in Fig.8. To STEX treated rice straw, WRV and saccharification rate increased with the treating time 
during the initial 120min, when the treatment with sulfur trioxide duration was elongated the WRV began to decline rapidly and the saccharification rate just decreased slightly (Fig.8A), we suggest that a little of carbide might form in the rice straw when time of STEX was too long and cellulose became more hydrophobic. To dilute alkali-treated method, the WRV increased during the initial $120 \mathrm{~min}$ and then became stable, the saccharification rate increased within initial 180min (Fig.8B). The dilute alkali-treated method removed the lignin in lignocellulosic slowly, slightly destructed the internal structure of cellulose and the off lignin lignocellulosic structure will be opened gradually so that the WRV and the saccharification rate increased. The change of the saccharification rate and WRV of the sulfur trioxide followed by alkali-treated rice straw are shown in Fig.8C, the WRV increased within initial $60 \mathrm{~min}$ but decreased after $60 \mathrm{~min}$ and the saccharification rate increased and became stable after $120 \mathrm{~min}$.

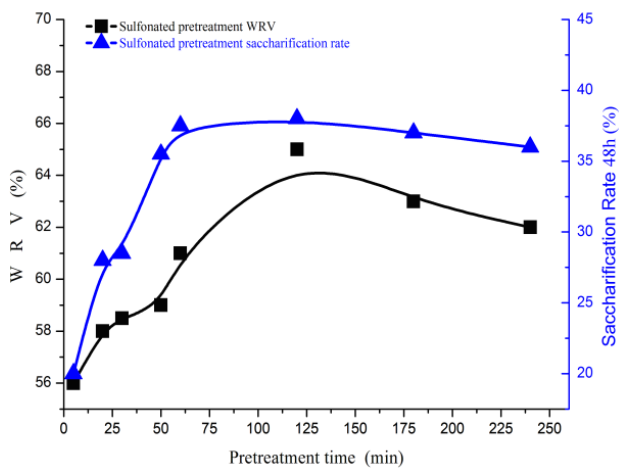

(A)

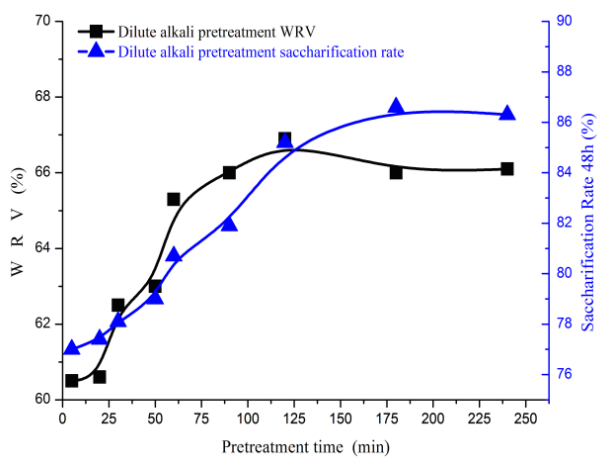

(B)

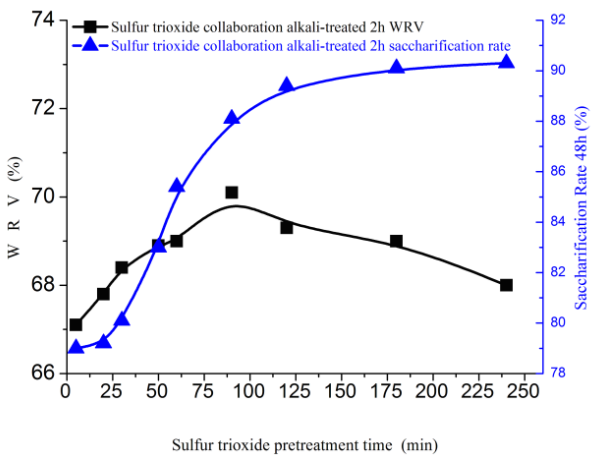

(C)

Figure 8. The impacts of WRV on saccharification rate by pretreatment. - $\mathbf{\Lambda}-$, saccharification rate; - $\bullet-$, WRV; (A) rice straw was treated for 4 hours at $50^{\circ} \mathrm{C}$ by sulfur trioxide; (B) rice straw was treated for 4 hours at $50^{\circ} \mathrm{C}$ by $1 \% \mathrm{w} / \mathrm{v} \mathrm{NaOH}$; (C) straw was treated with sulfur trioxide for 4 hours followed by $1 \%$ $\mathrm{w} / \mathrm{v} \mathrm{NaOH}$ treatment for 2 hours at $50^{\circ} \mathrm{C}$. 


\section{Future perspective}

STEX for the pretreatments of cornstalk, rape straw, wheat straw had also been researched in our lab, and the STEX method exibited significant effects on the enhancement of enzyme hydrolysis of these herbs, that means STEX can act as a universal method for lignocellulosic pretreatment, and mdoderate requirements for performing STEX may improve competitiveness of the renewable energy from biomass. While there are also several aspects, which need to be researched for applying the STEX into commercial-scale application (industry), such as pretreatment equipment, clean technology in lower cost, and how to attain the utter utilization of lignocelluloses in order to manufacture high-purity cellulose. Meanwhile, the optimization of the STEX pretreatment process, clean and low-cost application of lignin black liquor and the research of high-efficiency pretreatment technology in the farmland are imminent. Commercial-scale application approach of rice straw with the STEX in the future is showed in Fig.9.

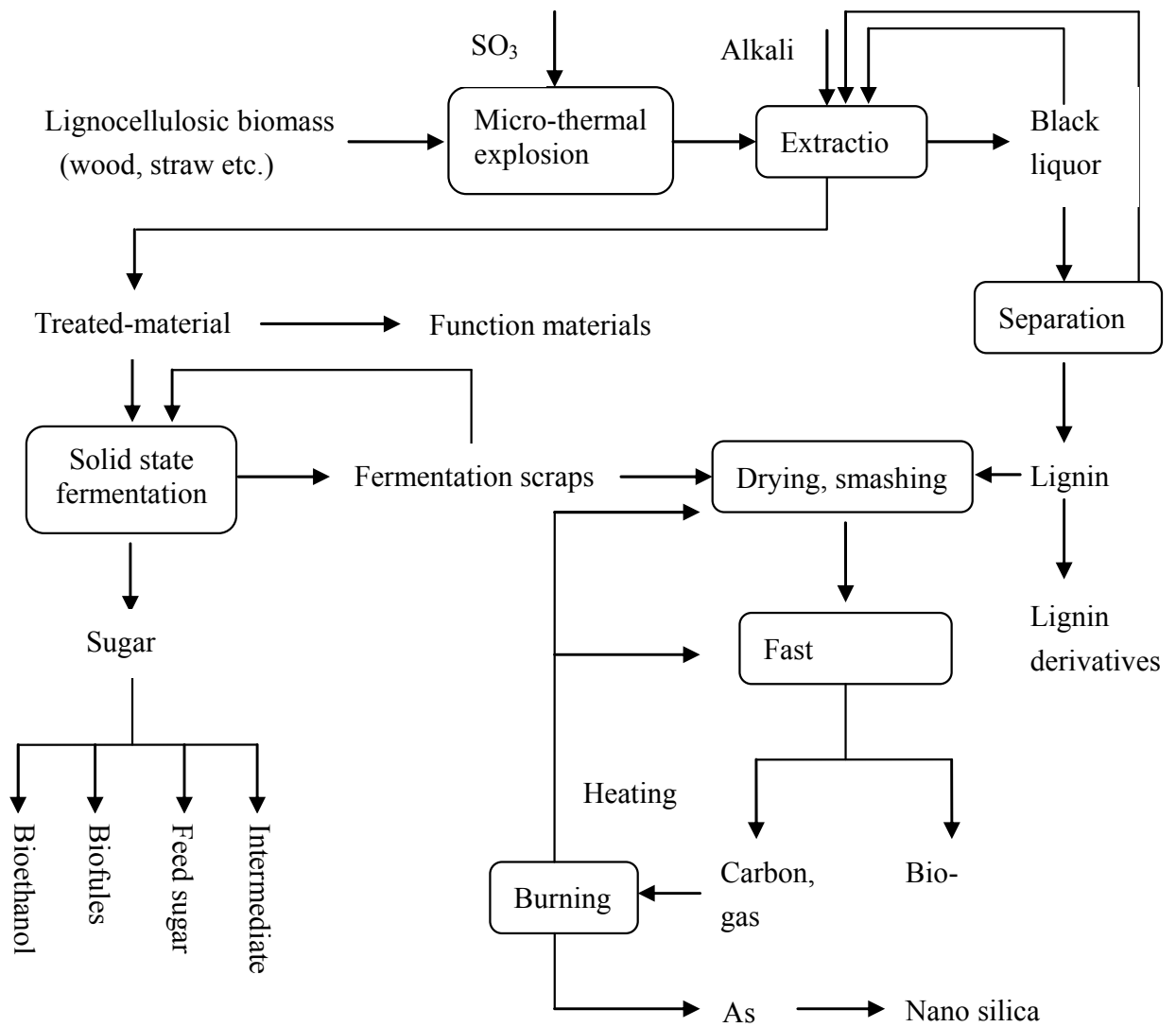

Figure 9. A platform of $\mathrm{SO}_{3} /$ alkali processing technology to achieve each component of straw and utter utilization of biomass 


\section{Author details}

Ri-Sheng Yao and Feng-He Li

Hefei University of Technology, AnHui, China

\section{References}

A.T.W.M. Hendriks, G. Zeeman, (2009) Pretreatments to enhance the digestibility of lignocellulosic biomass. Bioresource Technology 100, 10-18.

Balint Sipos, Emma Kreuger, Sven -Erik Svensson, Kati Reczey, Lovisa Bjornsson, Guido Zacchi, (2010) Steam pretreatment of dry and ensiled industrial hemp for ethanol production. Biomass \& Bioenergy 34, 1721-1731.

Brownell, H.H., Yu, E.K.C., Saddler, J.N., (1986) Steam-explosion pretreatment of wood: effect of chip size, acid, moisture content and pressure drop. Biotechnol. Bioeng. 28, 792-801.

Chang, V.S., Holtzapple, M.T., (2000) Fundamental factors affecting enzymatic reactivity. Appl. Biochem. Biotechnol., 5-37.

Das, M., and Chakraborty, D. (2009) Effects of alkalization and fiber loading on the mechanical properties and morphology of bamboo fiber composites. II. Resol matrix," J. Appl. Polym. Sci. 112, 447-453.

Delgenés, J.P., Penaud, V., Moletta, R., (2002) Pretreatments for the enhancement of anaerobic digestion of solid wastes Chapter 8. In: Biomethanization of the Organic Fraction of Municipal Solid Wastes. IWA Publishing, pp. 201-228.

Dieter K., Hans-Peter S. and Thomas H. (2003) polysaccharose II-Eukaryotes polysaccharide Chapter 10, cellulose, In: Biopolymers, Wiley-vch publishing, pp, 248-289.

Fengel, D., Wegener, G., (1984) Wood: Chemistry, Ultrastructure, Reactions. De Gruyter, Berlin.

Goering, H. K., and Van Soest, P. J. (1970) Forage fiber analyses (apparatus, reagent, procedure, and some application), Agricultural Handbook No. 379, Agricultural Research Service- United States Department of Agriculture (USDA), Washington D.C., 1-20.

Goswami, P., Blackburn, R. S., El-Dessouky, H. M., Taylor, J., and White, P. (2009) Effect of sodium hydroxide pre-treatment on the optical and structural properties of lyocell, Eur. Polym. J. 45, 455-465.

Hon, D.N.S. (1996) Functional polymers: a new dimensional creativity in lignocellulosic chemistry, in: Chemical Modification of lignocellulosic materials, pp.1-10. New York: Marcel Dekker.

Iranmahboob, F. Nadim and S. Monemi, (2002) Optimizing previous ermacid-hydrolysis: next term a critical step for production of ethanol from mixed wood chips, Biomass and Bioenergy, 22:401-404.

Keikhosro K., et al. (2006) Conversion of rice straw to sugars by dilute-acid hydrolysis. Biomass and Bioenergy, 30: 247-253.

Laser, M., Schulman, D., Allen, S.G., Lichwa, J., Antal Jr, M.J., Lynd, L.R., (2002) A comparison of liquid hot water and steam pretreatments of sugar cane bagasse for bioconversion to ethanol. Bioresour. Technol. 81, 33-44.

Li F.H., Hu H.J., Yao R.S., Wang H., Li M.M. (2012) Structure and saccharification of rice straw pretreated with microwave-assisted dilute lye. Industrial $\mathcal{E}$ Engineering Chemistry Research. 
Li F.H., Yao R.S., (2012) Influence of low temperature plasma on the structure and saccharification of rice straw. Internal communication.

Li, R. J., Fei, J. M., Cai, Y. R., Li, Y. F., Feng, J. Q., and Yao, J. M. (2009) Cellulose whiskers extracted from mulberry: A novel biomass production, Carbohyd. Polym. 76, 94-99

Liu, C. G., and Wyman, C. E. (2005) Partial flow of compressed-hot water through corn stover to enhance hemicellulose sugar recovery and enzymatic digestibility of cellulose, Bioresour. Technol. 96, 1978-1985.

Mosier, N., Wyman, C. E., Dale, B. E., Elander, R. T., Lee, Y. Y., Holtzapple, M., and Ladisch, M. R. (2005) Features of promising technologies for pretreatment of lignocellulosic biomass, Bioresource Technol. 96, 673-686.

Mukhopadhyay, S., and Fangueiro, R. (2009) Physical modification of natural fibers and thermoplastic films for composites - A review. J. Thermoplast. Compos. 22,135-162.

Negro, M.J., Manzanares, P., Oliva, J.M., Ballesteros, I., Ballesteros, M., (2003) Changes in various physical chemical parameters of Pinus Pinaster wood after steam explosion pretreatment. Biomass Bioenergy 25, 301-308.

Nguyen, Q, (2004) Milestone completion report: evaluation of a two-stage dilute sulfuric previous termacid hydrolysisnext term process. Internal Report, National Renewable Energy Laboratory, Golden.

Palmowski, L., Muller, J., (1999) Influence of the size reduction of organic waste on their anaerobic digestion. In: II International Symposium on Anaerobic Digestion of Solid Waste. Barcelona 15-17 June, pp. 137-144.

Palonen, H., Thomsen, A.B., Tenkanen, M., Schmidt, A.S., Viikari, L., (2004) Evaluation of wet oxidation pretreatment for enzymatic hydrolysis of softwood. Appl. Biochem. Biotechnol. 117, 1-17.

Reith, J.H., Wijffels, R.H., Barten, H., (2003) Bio-methane \& Bio-hydrogen. Status and perspectives of biological methane and hydrogen production. Production of the Dutch biological hydrogen production, The Hague.

Taherzadeh, M. J., and Karimi, K. (2008) Pretreatment of lignocellulosic wastes to improve ethanol and biogas production: A review, Int. J. Mol. Sci. 9, 1621-651.

Taherzadeh, M. J., and Karimi, K. (2007) Enzyme-based hydrolysis processes for ethanol from lignocellulosic materials: A review, BioResources 2, 707-738.

Vitz, J., Erdmenger, T., Haensch, C., Schubert, U.S. (2009) Extended dissolution studies of cellulose in imidazolium based ionic liquids. Green Chem. 11, 417-424.

Wu, M.M., Chang, K., Gregg, D.J., Boussaid, A., Beatson, R.P., Saddler, J.N. (1999) Optimization of steam explosion to enhance hemicellulose recovery and enzymatic hydrolysis of cellulose in softwoods. Appl. Biochem. Biotechnol., 47-54.

Yao, R. S., Hu, H. J., Deng, S. S., Wang, H., and Zhu, H. X. (2011) Structure and saccharification of rice straw pretreated with sulfur trioxide micro-thermal explosion collaborative dilute alkali, Bioresour. Technol.102(10), 6340-6343.

Ye S., Jay J C. (2005) Dilute acid pretreatment of rye straw and bermudagrass for ethanol production. Biochem. Biotechnol., 96(14):1599-1606.

Zhao, X. B., Cheng, K. K., and Liu, D. H. (2009) Organosolv pretreatment of lignocellulosic biomass for enzymatic hydrolysis. App. Microbiol. Biot. 82, 815-827.

Zheng, Y., Lin, H.M., Tsao, G.T. (1998) Pretreatment for cellulose hydrolysis by carbon dioxide explosion. Biotechnol. Progr., 14, 890-896. 